\title{
Effectiveness of Structured Teaching Program Regarding Knowledge of Drug Abuse Among Students
}

\author{
Naseemullah $^{1^{*}} \quad$ Muhammad Hussain $^{2} \quad$ Iram Majeed $^{3} \quad$ Muhammad Afzal $^{4}$ Syed Amir Gilani ${ }^{5}$ \\ Syed Amir Gilani ${ }^{4}$ \\ 1. Student of BS Nursing, The University of Lahore, PO box 53700, Lahore, Pakistan \\ 2. Assistant Professor, The University of Lahore, PO box 53700, Lahore, Pakistan \\ 3. Lecturer, The University of Lahore, PO box 53700, Lahore, Pakistan \\ 4. Associate Professor, The University of Lahore, PO box 53700, Lahore, Pakistan \\ 5. Philosophy Doctor, The University of Lahore, PO box 53700, Lahore, Pakistan.
}

\begin{abstract}
Background: Substance abuse among school students is a major and serious health issue. The most alarming fact is that the age for taking substance abuse is progressively falling. There is a paucity of literature on the effectiveness of existing interventions or awareness program to reduce the drug use among students in underdeveloped countries. It would be vital to examine the knowledge of students regarding drug abuse and should administer health education on the awareness and health hazards to prevent and control drug abuse. Aim of the study: Aim of the study was to assess the effectiveness of structured teaching program regarding knowledge of drug abuse among school students. Methods: A quasi-experimental study was chosen, one group pre and post-test design was used. Simple random sampling technique was used. The sample size was 100 high school students with mean age of 17.63 years. Data were collected by administering a knowledge questionnaire before and after the health education programme. Results: The result showed that the school students, in general, having some knowledge regarding drug abuse in the pre-test and the mean knowledge score was 28.92. There was a marked gain in knowledge in post-test score that was 41.19. It indicates a significant improvement in students' knowledge. Conclusion: Study shows that knowledge of drug abuse and behavior of the students can be changed by educational interventions.
\end{abstract}

Keywords- Effectiveness, Structured teaching programme, knowledge, Drug abuse, Student.

DOI: $10.7176 / \mathrm{JEP} / 10-1-12$

\section{Introduction}

Since prehistoric times, people almost in all cultures have used psychoactive substances. These substance act on the brain to alter the mind and as a result alter the way reality is perceived and also the way people feel. Most people continue use of drugs for the relief of negative emotional states like anxiety, depression, fear, fatigue or boredom and they disperse from routine work by the way of producing an altered state of consciousness. Drugs and alcohol used continuously in various religious circumstances (Gali WS. 2015).

Globally 29.4 million people are affected by drug use and related problems. This means that the abuse of drugs is harmful to physical and mental health which require immediate treatment (Global Burden of Disease Study 2015).

Drugs abuse may induce symptoms that are similar to mental illnesses. It mostly appears in the intoxicated state or during the withdrawal state. Psychiatric disorders induced by substance abuse may persist long after detoxification such as a prolonged depression or psychosis after the cocaine and amphetamine abuse. A review of the literature suggested that the age of 18 to 25 years in many countries in university students that substances use tends to peak at particular risk (Zaman et al., 2015).

During the time of transition, the risk for substance abuse greatly increase. Moving to the new area or changing schools are considered risky times for teenagers. At the age of adolescent, the stage when they move towards from elementary level to middle level they face many environmental, academic or social problems. The children are exposed for the first time to substance abuse such as cigarette and alcohol during this period. As they took admission at high schools the teens are prone to easily take drugs because of the easy availability which used by older teens and many others social activities where drug are used (National Institute on Drug Abuse, 2014).

Increasing substance abuse is a public health concern affecting the young generation, their physical, psychosocial health and gradually the whole life of an individual. Particularly the most alarming fact is that taking substance abuse for the first time is progressively falling. It is an urgent need to plan health education to have knowledge on the magnitude and types of substance abuse among students and their attitude and behavior towards its control and preventions (Osman et al., 2016).

Behavioural treatments help to engage people in substance use disorder treatment, modifying their attitude and behaviours related to drug use through increasing their life skills to overcome stressful circumstances and other environmental cues that trigger intense craving for drugs and ready for another cycle of compulsive use. 
Behaviours therapy may also enhance the effectiveness of medications and help people in treatment longer (National Institute on Drug Abuse, 2014).

Educational programmes on school level should include relevant information regarding substance abuse and type of treatment as well as appropriate treatment services. School and public health programmes should address the harmful effects of substance use and their addictive nature. The study shows that the majority of the students have adequate knowledge regarding the harmful effects of addictive substance but limited knowledge of treatment options. This indicates the need for more awareness about the treatment of substance abuse via school lectures, media, and campaigns at a larger level in communities (Nebhinani, N., Nebhinani, M., Misra, A. K., \& Grewal, S. 2013).

AIM OF THE STUDY:

The aim of the study was to assess the effectiveness of structured teaching programme regarding knowledge of drug abuse among students.

SIGNIFICANCE OF THE STUDY:

To develop strategies for modification of drug abuse behavior of students to improve their health status and quality of life through educational sessions and awareness programs in the school.

\section{Literature Review}

A report shows that about 24.6 million Americans at the age of approximately 12 or older were current illegal drug users, it means they had used illicit drugs a month prior to the survey. About 9.4 percent of the population at the age of 12 or older using illicit drugs which include marijuana/hashish, cocaine, heroin, hallucinogens, inhalants and prescription-type psychotherapeutics (pain relievers, tranquilizers, stimulants, and sedatives) are used non medically (Rockville, MD in 2014).

Previously a study conducted in Pakistan and the result shows that the overall prevalence of substance abuse was $52.2 \%$ for at least one substance. Smoking is most commonly used with $23 \%$, alcohol $8.5 \%$, Naswar $6.1 \%$, heroin $4.7 \%$ and $3 \%$ others illicit drug are used. Sex, personal pleasures, and depression are statistically significant predictors of substance abuse. The finding of the study reveals that males are strongly associated with substance use. The fact of high exposure and peer pressure for male students are the most common factors than female students. Moreover, Naswar and tobacco use are usually acceptable practice among males (Noureen. 2017).

According to the recent Drug Use in Pakistan, the estimated report shows that approximately 6.45 million (5.8\%) people at the age of 15-64 years use synthetic substances or prescription drugs for non-medical purposes means addicted in the past 12 months. In 2012 Pakistan's Ministry of narcotics control, Pakistan bureau of statistics and the UN Office on Drug and Crime got outcomes of this report with the help of collaborative research (Majeed, Sherazi, Arooj, \& Afzal, 2018).

A study shows the prevalence of substance abuse among adolescent school students, the mean age was $15.26 \pm 1.59$ years. The prevalence of substance abuse among school students was $8.8 \%$, and the majority of them used substance once in a month or less. The students they are most commonly using drugs are included tramadol (83.3\%), cannabis $(27.8 \%)$, and alcohol (16.7\%), with a mean age of onset of smoking, is $16.06 \pm 1.39$ years and a mean age of onset of substance abuse is $16.5 \pm 1.098$ years (Negm, M. G. and A. A. Fouad, 2014).

A study conducted to assess the knowledge regarding drug abuse and the finding revealed that more than half $(72 \%)$ students had below average knowledge followed by $20 \%$ had average knowledge and only $8 \%$ had good knowledge regarding drug abuse. The result shows that majority of the students had below average knowledge. It is recommended that the teachers and health professionals should be delivered health education on the knowledge and harmful effects of drug abuse (Kaur \& Kaur, 2018).

A study conducted in 2015 to determine the effectiveness of an awareness program regarding knowledge of substance abuse and its consequences among students. Pre-test scoring shows that $7.6 \%$ having good knowledge and after post-test, the knowledge score reached up to $52.8 \%$. There was no statistically significant level of 0.05 between the demographic variables and knowledge score. Overall the teaching session improves the knowledge level of the students regarding drug abuse and its consequences (Nayak \& Jose, 2015).

In 2016 a study conducted and revealed that $41,(6 \%)$ of the students have the information of the effects of drugs and $78.6 \%$ of them believed that drug abuse could be quit if someone wants. According to $42 \%$ of the school students, drug abuse resulted from bad communication among the parents and their kids. The study discovered that $16.4 \%$ of the students currently smoked, $11.3 \%$ drink alcohol and $2.5 \%$ had used drugs. A measurable major difference was found between the occurrence of drug use according to genders, tobacco use beginning age, family nature and drug experimental behaviors $(\mathrm{p}<0.05)$ (Adibelli, D., \& Olgun, S. 2016).

A recent survey shows a drop in alcohol, tobacco and substance use with the help of educational and awareness programmes in American teenagers in grade $8^{\text {th }}, 10^{\text {th, }}$ and $12^{\text {th }}$ (the University of Michigan. 2015). The practice of tobacco use and alcohol were at a measured low in 2015, and presently at the lowest rate, they have got since 1975. Prescription drugs, heroin, bath salt, crack cocaine, hallucinogens, synthetic marijuana, and 
amphetamine have all declined in use among Americans students in grade $8^{\text {th }}, 10^{\text {th }}$ and $12^{\text {th }}$ (the University of Michigan. 2015).

\section{Methodology}

Quasi-experimental, one group pre and post study design used with a quantitative method of data collection. Data were collected from 100 high school students of class $9^{\text {th }}$ and $10^{\text {th }}$, using simple random sampling technique. A well adopted questionnaire was used, Participants were well informed. Data was analysed through SPSS 21. The study was conducted in 4 months of period, (September 2018 to December 2018).

\section{Results}

This section presents the outcomes of the study.

This chapter includes three portions of analysis. The first analysis was done of demographic data. It gives us details of demographic questions. Descriptive analysis was used to find out the distribution of each characteristic.

\section{Section I}

The post-test analysis revealed there is significant association was found with age, monthly pocket money, class of study in school and source of information regarding drug abuse at $p<0.05$ and no association could be found with other demographic variables of high school students as showed in table 01.

Table 01: Shows the demographic characteristics of the participants.

\begin{tabular}{|c|c|c|c|c|}
\hline \multicolumn{3}{|l|}{ Variables } & Frequency & Percentage \\
\hline \multicolumn{3}{|l|}{ 1. Age Group } & \multicolumn{2}{|c|}{ Mean $=17.63$} \\
\hline \multirow[t]{2}{*}{ 2.Religion } & \multicolumn{2}{|l|}{ Islam } & 88 & $88 \%$ \\
\hline & \multicolumn{2}{|l|}{ Other } & 12 & $12 \%$ \\
\hline \multirow{2}{*}{$\begin{array}{l}\text { 3.Class of } \\
\text { study }\end{array}$} & \multicolumn{2}{|l|}{$9^{\text {th }}$} & 50 & $50 \%$ \\
\hline & \multicolumn{2}{|l|}{$10^{\text {th }}$} & 50 & $50 \%$ \\
\hline \multirow{3}{*}{$\begin{array}{l}\text { 4.Place of } \\
\text { stay }\end{array}$} & \multicolumn{2}{|l|}{ Home } & 75 & $75 \%$ \\
\hline & \multicolumn{2}{|l|}{ Hostel } & 5 & $5 \%$ \\
\hline & \multicolumn{2}{|c|}{ Relative home } & 20 & $20 \%$ \\
\hline \multirow[t]{3}{*}{ 5.Type of family } & \multicolumn{2}{|l|}{ Nuclear } & 41 & $41 \%$ \\
\hline & \multicolumn{2}{|l|}{ Joint } & 23 & $23 \%$ \\
\hline & \multicolumn{2}{|c|}{ Single parent } & 36 & $36 \%$ \\
\hline \multirow{4}{*}{$\begin{array}{l}\text { 6.Living status of } \\
\text { parents }\end{array}$} & \multirow[t]{2}{*}{ Father } & Alive & 43 & $43 \%$ \\
\hline & & Dead & 15 & $15 \%$ \\
\hline & \multirow[t]{2}{*}{ Mother } & Alive & 34 & $34 \%$ \\
\hline & & Dead & 08 & $08 \%$ \\
\hline \multirow{4}{*}{$\begin{array}{l}\text { 7.Monthly pocket } \\
\text { money }\end{array}$} & \multicolumn{2}{|c|}{$500-1000$} & 43 & $43 \%$ \\
\hline & \multicolumn{2}{|l|}{1500} & 15 & $15 \%$ \\
\hline & \multicolumn{2}{|l|}{2000} & 34 & $34 \%$ \\
\hline & \multicolumn{2}{|c|}{2500 or Above } & 08 & $08 \%$ \\
\hline \multirow[t]{2}{*}{ 8.Part-time job } & & Yes & 26 & $26 \%$ \\
\hline & & No & 74 & $74 \%$ \\
\hline \multirow{4}{*}{$\begin{array}{l}\text { 9. Read literature } \\
\text { regarding drug } \\
\text { abuse }\end{array}$} & \multicolumn{2}{|c|}{ Very often } & 43 & $43 \%$ \\
\hline & \multicolumn{2}{|c|}{ Sometime } & 15 & $15 \%$ \\
\hline & \multicolumn{2}{|l|}{ Rarely } & 34 & $34 \%$ \\
\hline & \multicolumn{2}{|l|}{ Never } & 08 & $08 \%$ \\
\hline \multirow{4}{*}{$\begin{array}{l}\text { 10.Listen or watch } \\
\text { regarding drug } \\
\text { abuse }\end{array}$} & Very of & & 48 & $48 \%$ \\
\hline & Sometir & & 19 & $19 \%$ \\
\hline & Rarely & & 27 & $27 \%$ \\
\hline & Never & & 06 & $06 \%$ \\
\hline
\end{tabular}

Research Hypothesis - There is an effect of a structured teaching programme regarding knowledge of drug abuse among the students. 
Table 02: Area wise paired ' $t$ ' test, pre and post knowledge

\begin{tabular}{|l|l|l|l|l|l|}
\hline \multirow{2}{*}{ Area } & \multicolumn{3}{|l|}{ Knowledge Score } & \multirow{2}{*}{$\begin{array}{l}\text { Mean } \\
\text { Difference }\end{array}$} \\
\cline { 2 - 5 } & Pre & $\%$ & Post & $\%$ & 2.350 \\
\hline Concept of drug abuse & 3.15 & 39.4 & 5.50 & 68.8 & 290 \\
\hline Predisposing factors & .47 & 47 & .76 & 76 & .290 \\
\hline Effects & 2.96 & 37 & 5.73 & 71.9 & 2.770 \\
\hline Withdrawal symptoms & 3.09 & 51.5 & 5.19 & 86.5 & 2.10 \\
\hline Prevention \& treatment & 2.99 & 42.7 & 5.28 & 75.4 & 2.290 \\
\hline
\end{tabular}

Figure: 01 Shows difference of pre and post-test knowledge.



Table 02 and figure 01 shows that the level of knowledge on drug abuse is higher in post-test as compare to pre-test knowledge. Hence the null hypothesis is rejected and the research hypothesis is accepted. This show that health education programme in each area as effective in increasing the knowledge score of high school students.

\section{Section II}

This section deals regarding the normality of the data.

Table 03: Show Tests of Normality

\begin{tabular}{|l|c|c|c|c|c|c|}
\hline \multirow{2}{*}{} & \multicolumn{3}{|c|}{ Kolmogorov-Smirnov $^{\mathrm{a}}$} & \multicolumn{3}{c|}{ Shapiro-Wilk } \\
\cline { 2 - 7 } & Statistic & $\mathrm{df}$ & Sig. & Statistic & df & Sig. \\
\hline Pre & .111 & 100 & .004 & .977 & 100 & .071 \\
Post & .130 & 100 & .000 & .972 & 100 & .032 \\
\hline
\end{tabular}

Above mentioned table 03 represent the normality of the data, the Kolmogorov-Smirnov and Shapiro-Wilk test apply and the finding shows that statistic values of pre-data were .111 and .977 with a significant value of .004 and .071 . While in post data presentation the statistic values were .130 and .972 with a significant value of .000 and .032 respectively.

\section{Figure 2: Shows the distribution of the data.}

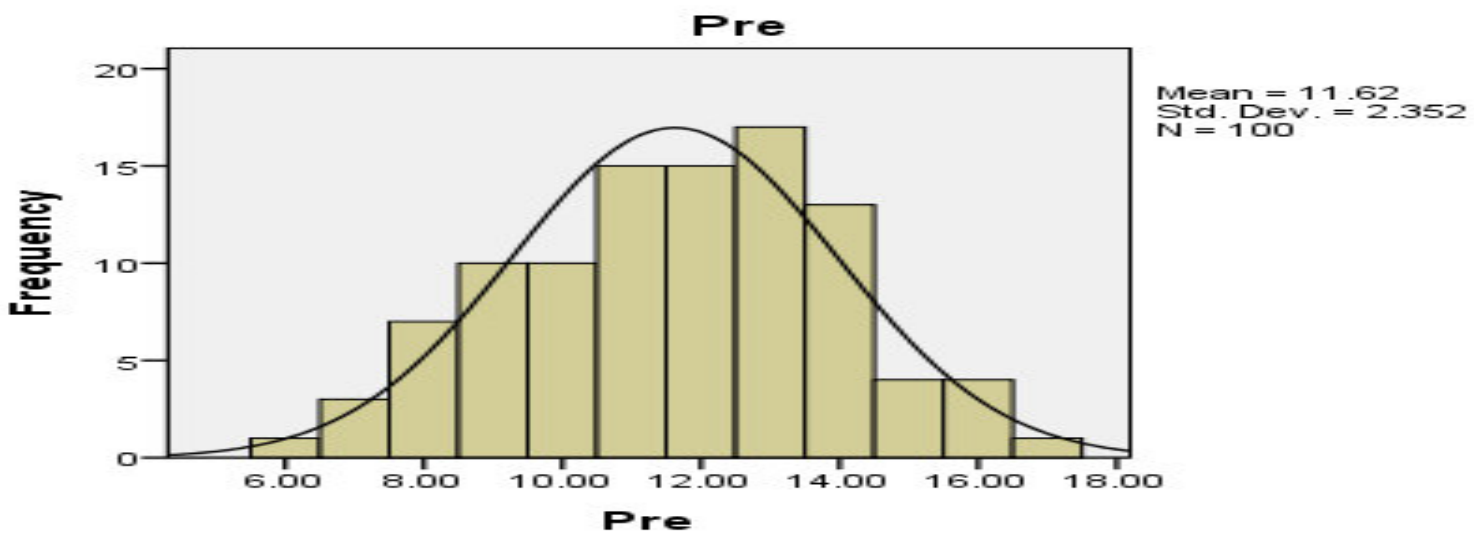

Figure 2 shows that the data was normally distributed in all concerned area. The total number of participants was 100 and the mean value is 11.62 with a standard deviation of 2.352 , which indicate the data was statistically significant.

\section{Section III}

This section explains the pre and post analysis of data by using paired ' $t$ ' test. 
Table 04: Paired Samples Statistics

\begin{tabular}{|l|l|l|l|l|l|}
\hline & Mean & Mean in \% & N & Std. Deviation & Std. Error Mean \\
\hline Pre Test & 28.92 & $53.55 \%$ & 100 & 6.298 & .630 \\
Post Test & 41.19 & $76.27 \%$ & 100 & 4.948 & .495 \\
\hline
\end{tabular}

The results of the study in table 04 shown that pre-test overall mean knowledge score of high school students regarding drug abuse was 28.92 (53.55\%). During post-test the students gain knowledge and the overall mean knowledge score of high school students reached up to $41.19(76.27 \%)$.

Table 05: the Paired difference between pre and post knowledge

\begin{tabular}{|l|l|l|l|l|l|l|}
\hline & \multicolumn{2}{|l|}{ Paired Differences } & \multirow{2}{*}{ 't' value } & \multirow{2}{*}{ sig } \\
\cline { 2 - 5 } & Mean & $\begin{array}{l}\text { Std. } \\
\text { Devia-tion }\end{array}$ & $\begin{array}{l}95 \% \\
\text { Confidence Interval of the Difference }\end{array}$ & & \\
\cline { 3 - 5 } & & Lower & -12.9 & -11.6 & -37.120 & .000 \\
\hline Pre and Post & 12.27 & 3.306 & Upper & & \\
\hline
\end{tabular}

Hence table 05 shows the difference between pre-test and post-test overall knowledge score was 12.27 and standard deviation of 3.306. So the results of the study shown the pre-test and post-test knowledge score that was statistically significant and the difference are due to the administration of structured teaching programme regarding the knowledge of drug abuse to high school students.

\section{Discussion}

This quasi-experimental study finds out the positive impact of education session on 100 high school students in Lahore. Finding of this study indicated that there is a significant effect of teaching programme on the students to improve their knowledge regarding drug abuse. Finding also shows that most of the respondents were not aware of the causes, effects, and prevention of drug abuse in pre-test result. After administering teaching session on drug abuse the students acquired knowledge regarding the causes, effects, and prevention or treatment strategies of drug abuse. The result shows that the education session was effective and gain better score in post-test result at $\mathrm{p}<0.05$.

A similar study was conducted on 69 school children aged 8-12 years participating in an after-school programme at India napolis. After obtaining the baseline information by questionnaire, the investigator conducted a 6 session educational programme to explore the effectiveness of teaching. The results from the study demonstrated that students who have a plan to resist drug use are more likely not to use drugs. The study also suggested that school programme was effective to gain knowledge as well as stop using drugs (Khande, A. M., 2018).

The finding of this study reveals that high school students have some knowledge regarding drug abuse. The students that exposed to some specific drugs or to the information regarding drug abuse had more knowledge in pre-test result.

A similar study was conducted among urban adolescents to assess the knowledge and attitude about the substances. The sample consisted of 240 elementary and high school students in the age range of 13-23 years. A multi-dimensional, self-reporting questionnaire was used. Knowledge about the consequences of consuming psychoactive substances positively correlated with the frequency of consuming that specific drug. Our findings could serve as the empirical basis for the re-evaluation of the current drug prevention programmes and programmes aimed at preventing other forms of risk behavior among children and adolescents (Adibelli, D., \& Olgun, S. 2016).

The finding of this study revealed that the respondents share different view regarding the effects of drug abuse. A study conducted and the result shows that an individual or youth, sustained substance abuse has many social and health problems. It has been linked to various forms of crime, violence, and traffic accidents. Empirical evidence has also pointed out to a strong association between substance abuse by youth and a number of accidental injuries including traffic, drowning, poisoning, burns and falls, as well as premeditated injuries such as interpersonal violence, suicides, child abuse and sexual violence (Jan. F., et al. 2018).

\section{Hypothesis testing}

Hypothesis testing was done to assess the effects of a structured teaching programme regarding knowledge of drug abuse among students at selected high school in Lahore. Paired ' $t$ ' test used to test the hypothesis and difference in the level of knowledge between pre-test and post-test identified.

The overall mean score of pre-test is $28.92(53.5 \%)$ and the overall mean score of post-test knowledge was $41.19(77.5 \%)$. Based on the paired ' $t$ ' value of the finding $\mathrm{H}_{0}$ is rejected, as there were significant effects of educational interventions assessed by post-test result of high school students regarding drug abuse.

Based on the findings of ' $\mathrm{t}$ ' value, $\mathrm{H}_{1}$ was accepted, as there were significant effects of structured teaching program regarding knowledge of drug abuse among students identified in post-test with a significant value of 
$<0.05$.

\section{Conclusion}

The major findings of the study revealed that the majority of high school students had an inadequate level of knowledge about drug abuse by the mean value as 28.92 as presented in the pre-test. However, the result of posttest mean knowledge was significantly increased up to 42.12 that indicate the effectiveness of the teaching program.

Data analysis and findings of the present study concluded that there was a significant difference between the pre-test knowledge level and post-test knowledge level of high school students regarding drug abuse. The mean knowledge score of 100 students during the pre-test was 28.92 whereas it had increased up to 42.12 during the post-test as effectiveness of structured teaching programme. Therefore the difference assessed was 12.27 between pre-test and post-test. Hence on-going teaching and health education programs can further improve the knowledge of school students.

Prevention is better than cure, and this is very much true of drug abuse. Our education system should be made the right place where they imbibe healthy values. The personality of youth is shaped as he passes through the portals of schools and colleges. It needs health workers and teachers to strive for preventing and controlling drug use among students.

The health education programme for students on drug abuse could help them to maintain their personality and optimal health. Assessment of knowledge on drug abuse among school students and teaching/educating them about drug abuse is the main concept of the study. This will help the students to gain knowledge on drug abuse in the concerned areas.

After the introduction of the health education programme, the post-test measures showed that there is a significant increase in the knowledge of the regarding drug abuse.

\section{ACKNOWLEDGEMENT}

This research work was not possible without the help and encouragement of many individuals to whom I am really very grateful. First and foremost, I am very thankful to Mr. Muhammad Afzal (The Principal of Lahore School of Nursing) who encourage and allow me for this study. Mr. Muhammad Hussain for being my preceptor and the greatest inspiration for my work when I was in troubles to perform research work, and who has been supportive and always show a willingness to guide me till the completion of this research work. I am also very thankful to Ms. Iram Majeed, encouraging me throughout the whole research process and freely offered their precious time to help me. I am also grateful to my teachers Sir Muhammad Azhar, Ms. Kousar Parveen, my best friends and all those who I contacted during this process. I also thank to the management of the University of Lahore.

Last but not the least, I would like to present special thanks to my parents (May they live long), my younger brother, and my wife who provided endless moral, financial and motivational support for me during my whole academic duration.

\section{References}

Adibelli, D., \& Olgun, S. (2016). Knowledge, attitude and behavior of health college students related to drug abuse. The ulutas medical journal, 2(2), 90-100.

Gali, WS. (2015). Principles and Practice of Psychiatric Nursing. 9th ed. New Delhi: Elsevier.

Global Burden of Disease Study (2015). DALYs and HALE Collaborators, "Global, regional, and national disability-adjusted life years (DALYs) for 315 diseases and injuries and healthy life expectancy (HALE), 1990-2015:, The Lancet, vol.388, No.10053 (2016),pp. 1603-1658.

Jan, F., Ahmad, P., M., \& Ahmad, N., D. (2018). A study to assess the effectiveness of structured teaching programme on knowledge regarding substance abuse among adolescents in selected school (jawaharnavodaya vidiyalia khanpora) of district budgam, jammu an kashmir. Int. J. of Adv.Res. 6 (1). 956964] (ISSN 2320-5407).

Kaur, R., \& Kaur, G. (2018). A Descriptive Study to assess Knowledge of Teenagers Regarding Drug abuse at Sri Guru Harkrishan Sen. Sec. School, Majitha Road, Amritsar. International Journal ofNursing Education and Research, 6(1), 37-38.

Khande, A. M. (2018). Impact of health education program on knowledge of students towards drug abuse in selected collegesofbelagavi. International journal of scientific research, 7(5).

Majeed, M. H., Sherazi, S. A. A., Arooj, S., \& Afzal, M. Y. (2018). Addiction in Pakistan-Time to be taken seriously? Asian journal of psychiatry, 35, 36-37.

Nayak, A. K., \& Jose, T. T. (2015). A study to determine the effectiveness of an awareness programme on knowledge on substance abuse and its consequences among the students of a selected preuniversity college of udupi district, karnataka. Nitte University Journal of Health Science, 5(1). 
National Institute on Drug Abuse (2014). Preventing Drug Abuse among Children and Adolescents:A ResearchBased Guide for Parents, Educators, and Community Leaders (3rd Edition) (NIHPublication No. 044212[A]). Rockville, MD, 2014.

Nebhinani, N., Nebhinani, M., Misra, A. K., \& Grewal,S. 2013). Substance-related knowledge and attitude in school andcollege students. German Journal of Psychiatry, 16(1), 15-19.

Osman, T., Victor, C., Abdulmoneim, A., Mohammed, H., Abdalla, F., Ahmed, A., . Mohammed, W. (2016). Epidemiology of substance use among university students in Sudan. Journal of Addiction, 2016.

Zaman, M., Razzaq, S., Hassan, R., Qureshi, J., Ijaz, H., Hanif, M., \& Chughtai, F. R. (2015). Drug abuse among the students Orginal Article. Journal of Addiction. 